02

\title{
Люминесценция Pd и Pt бензогидропорфиразинов в ближнем ИК диапазоне
}

\author{
() П.П. Першукевич ${ }^{1}$, Д.И. Волкович ${ }^{1}$, Е.А. Макарова ${ }^{2}$, Е.А. Лукьянец ${ }^{2}$, К.Н. Соловьёв 1 Ф \\ ${ }^{1}$ Институт фоизики им. Б.И. Степанова НАН Беларуси, \\ 220072 Минск, Беларусь \\ ${ }^{2}$ Научно-исследовательский институт органических полупродуктов и красителей (НИОПИК), \\ 123995 Москва, Россия \\ ๑ e-mail: solovyov@imaph.bas-net.by
}

Поступила в редакцию 25.03.2020 г.

В окончательной редакции 25.03.2020 г.

Принята к публикации 07.07.2020 г.

Исследована фосфоресценция в ближнем ИК диапазоне при стационарном ламповом возбуждении новых трех палладиевых и трех платиновых комплексов бензоконденсированных гидропорфиразинов - аналогов фталоцианина, в молекуле которого один или два изоиндольных фрагмента замещены на гидрированное пиррольное кольцо, что дает макроциклы типа хлорина, бактериохлорина и изобактериохлорина - аналогов фотосинтетических пигментов. Впервые зарегистрированы спектры фосфоресценции комплексов трансдибензотетрагидропорфиразинов (и для платины, и для палладия), которые долгое время не удавалось обнаружить вследствие рекордного удаления 0-0-полос от видимой области (1.67 и $1.52 \mu \mathrm{m}$ для $\mathrm{Pd}$ и $\mathrm{Pt}), \mathrm{a}$ также из-за малого квантового выхода фосфоресценции. Обнаружена также флуоресценция этих комплексов в ближнем ИК диапазоне. На основе сопоставления результатов эксперимента с собственными и литературными данными для палладиевых комплексов ряда тетрапирролов показана приближенная аддитивность влияния структурных факторов - гидрирования пиррольных колец, азазамещения и бензозамещения на энергию нижнего триплетного состояния $T_{1}$. Полученные сведения существенны для целенаправленного создания излучателей в ближнем ИК диапазоне $(1.0-1.7 \mu \mathrm{m})$.

Ключевые слова: палладиевые и платиновые комплексы бензогидропорфиразинов, трансдибензотетрагидропорфиразин, аналоги фталоцианина, ближний ИК диапазон, спектр поглощения, спектр фосфоресценции, квантовый выход фосфоресценции, нижнее триплетное состояние, люминесценция синглетного кислорода.

DOI: $10.21883 /$ OS.2020.11.50169.119-20

\section{Введение}

В плане изучения связи физических свойств со строением молекул тетрапирролов и поиска путей их практических применений в ИК диапазоне нами были синтезированы Pd- и Pt-комплексы на основе новых аналогов фталоцианина и гидропорфиразинов - бензогидропорфиразинов. Ареногидропорфиразины [1-4] и их производные [5] - новый подкласс тетрапиррольных соединений с интенсивным поглощением в ближнем ИК диапазоне (БИК, NIR). Спектрально-люминесцентные свойства бензогидропорфиразинов - цинковых комплексов [6] и соответствующих свободных оснований $[6,7]$ - исследовались нашей научной группой. В работе [8] была зарегистрирована БИК-фосфоресценция комплексов палладия и платины с тетраметилтрибензодигидропорфиразином и октаметилдибензотетрагидропорфиразином с соседним расположением гидрированных пиррольных колец. В настоящей работе, чтобы избежать использования громоздких сокращений и длинных названий химических соединений, мы применили (по всему тексту) обозначения: Pd1 и Pt1 - для комплексов замещенного трибензодигидропорфиразина;
$\operatorname{Pd} 2$ и Pt2 - для комплексов замещенного дибензотетрагидропорфиразина с противоположным расположением гидрированных пиррольных колец (транс-); Pd3 и Pt3 - для их изомеров с соседним расположением гидрированных колец (цис-). Иными словами, аналоги хлоринов обозначены цифрой 1 , бактериохлоринов 2 , изобактериохлоринов - 3; в работе [8] - ТБТАХ, ДБТАБХ, ДБТАиБХ соответственно.

В работе [8] не удалось обнаружить фосфоресценцию молекул Pd2 и Pt2 (симметрия сопряженной системы $\left.D_{2 h}\right)$ ни при стационарном возбуждении на установке, охарактеризованной в $[9,10])$, ни при лазерном возбуждении на установке, описанной в [11]. В настоящей работе представлены результаты изучения фосфоресценции $\mathrm{Pd} 2$ и Pt2 при стационарном возбуждении с использованием новой техники - модульного спектрофлуориметра Fluorolog-3 производства фирмы HORIBA Scientific, а также - специально настроенной под задачу применявшейся ранее техники эксперимента $[9,10]$. Зарегистрирована флуоресценция этих объектов; её спектры расположены также в БИК диапазоне. Выборочно исследовано влияние внешней среды на параметры люминесценции. Получены дополнительные данные о спектрах 
фосфоресценции Pd1, Pt1, Pd3 и Pt3, а также сведения о фотостабильности.

\section{Объекты и методы эксперимента}

Синтез всех полученных комплексов палладия и платины подробно описан в работе [8]. Комплексы бензогидропорфиразинов были специально синтезированы для исследования фосфоресценции, однако в принципе они могут быть использованы как сенсибилизаторы для разных целей.

Структура объектов исследования показана на схеме, в которой (и далее по тексту) $\mathrm{M}$-металл ( $\mathrm{Pd}, \mathrm{Pt}$ и другие металлы).

Измерения скорректированных спектров люминесценции (фосфоресценции - PS и флуоресценции - FS) и спектров возбуждения люминесценции (PES и $\mathrm{FES}$ ) проводились на многофункциональном спектрофлуориметре модели Fluorolog-3 с Т-канальной оптикой производства фирмы HORIBA Scientific (Япония, США, Франция), а также на модернизированном спектрофлуориметрическом комплексе СДЛ-2 (ЛОМО, СССР), основанном на монохроматорах возбуждения и регистрации соответственно МДР-12 и МДР-23 [9,10]. В дальнейшем используются краткие названия этих комплексов соответственно Fluorolog-3 и Люмоскан (Lumoscan).

B комплексе Fluorolog-3 в качестве источника возбуждения использовалась стационарная ксеноновая лампа мощностью $450 \mathrm{~W}$, свет от которой пропускался через двойной монохроматор. Спектры фосфоресценции и спектры возбуждения фосфоресценции регистрировались в стандартной 90-градусной геометрии расположения осей монохроматоров, но при возбуждении, осуществляемом системой зеркал, под углом $22^{\circ}$ к нормали передней грани кюветы („на отражение“), с помощью дифракционного спектрометра iHR320-FAS (HORIBA Scientific) и охлаждаемой жидким азотом InGaAs линейной матрицы FL-1100-05 $(800-1700 \mathrm{~nm})$ в качестве детектора. При этом спектры обоих типов регистрировались в специальном режиме развертки по длинам волн возбуждения и регистрации фосфоресценции с получением в конечном итоге матрицы возбуждениярегистрации (Excitation-Emission Matrix, EEM). Затем из ЕЕМ выбирались кривые, соответствующие максимумам в спектре фосфоресценции или спектре возбуждения фосфоресценции.

На комплексе Lumoscan при измерении спектров фосфоресценции в БИК диапазоне (в отличие от обычной геометрии измерения спектров люминесценции под углом $90^{\circ}$ к направлению распространения возбуждающего света) был использован продольный вариант возбуждения с соосным расположением системы регистрации. Возбуждение образца осуществлялось излучением ксеноновой лампы ДКсШ-120 мощностью $120 \mathrm{~W}$, сфокусированным с помощью двухлинзового конденcopa, через стопу из четырех или пяти стеклянных фильтров. Образец располагался в точке совпадения фокусов задней линзы возбуждения и передней линзы системы регистрации. Максимумы полос пропускания фильтров, расположенные вблизи 560 и $500 \mathrm{~nm}$ с полуширинами около 200 и $100 \mathrm{~nm}$, показаны на рис. 1, $a$. При описанном продольном варианте возбуждения, кроме увеличения мощности возбуждения примерно на порядок, в поле зрения передней собирающей линзы попадало значительно большее количество возбужденных молекул, чем при поперечном. Как установлено экспериментально, в широком диапазоне регистрации $(900-1700 \mathrm{~nm})$ низкий уровень помех от возбуждающего и рассеянного света позволил получить надежные данные по спектрам фосфоресценции, в частности, в области $1600-1700 \mathrm{~nm}$. В качестве фотоприемника использовался InGaAs-фотодиод IGA-050-TE2-H с приемной площадкой диаметром $5 \mathrm{~mm}$ фирмы „ElectroOptical Systems Inc“ (Канада, США). Предварительно усиленный сигнал с фотодиода подавался на основной усилитель с синхродетектором Lock-in nanovoltmeter type 232B (Польша, США).

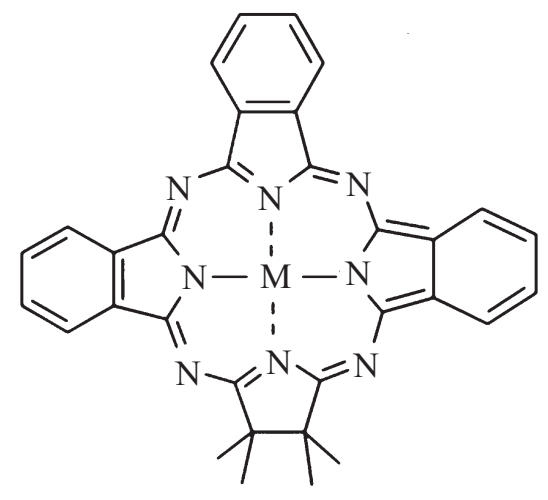

Pd1

Pt1

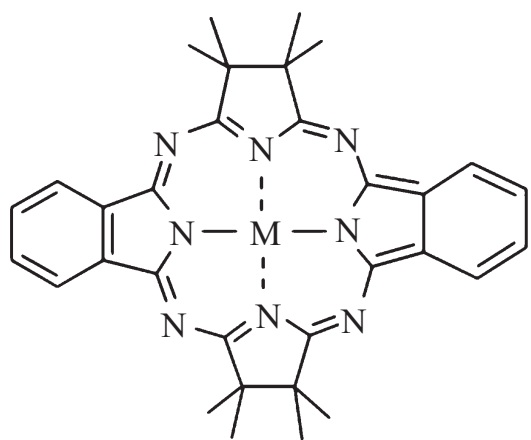

$\mathrm{Pd} 2$

Pt2

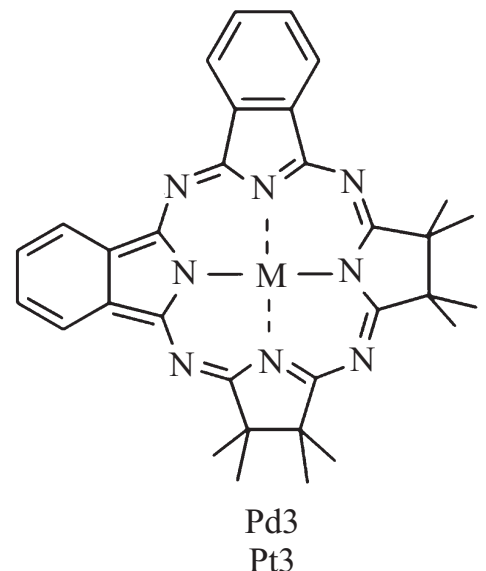

Pt3

Схема. 

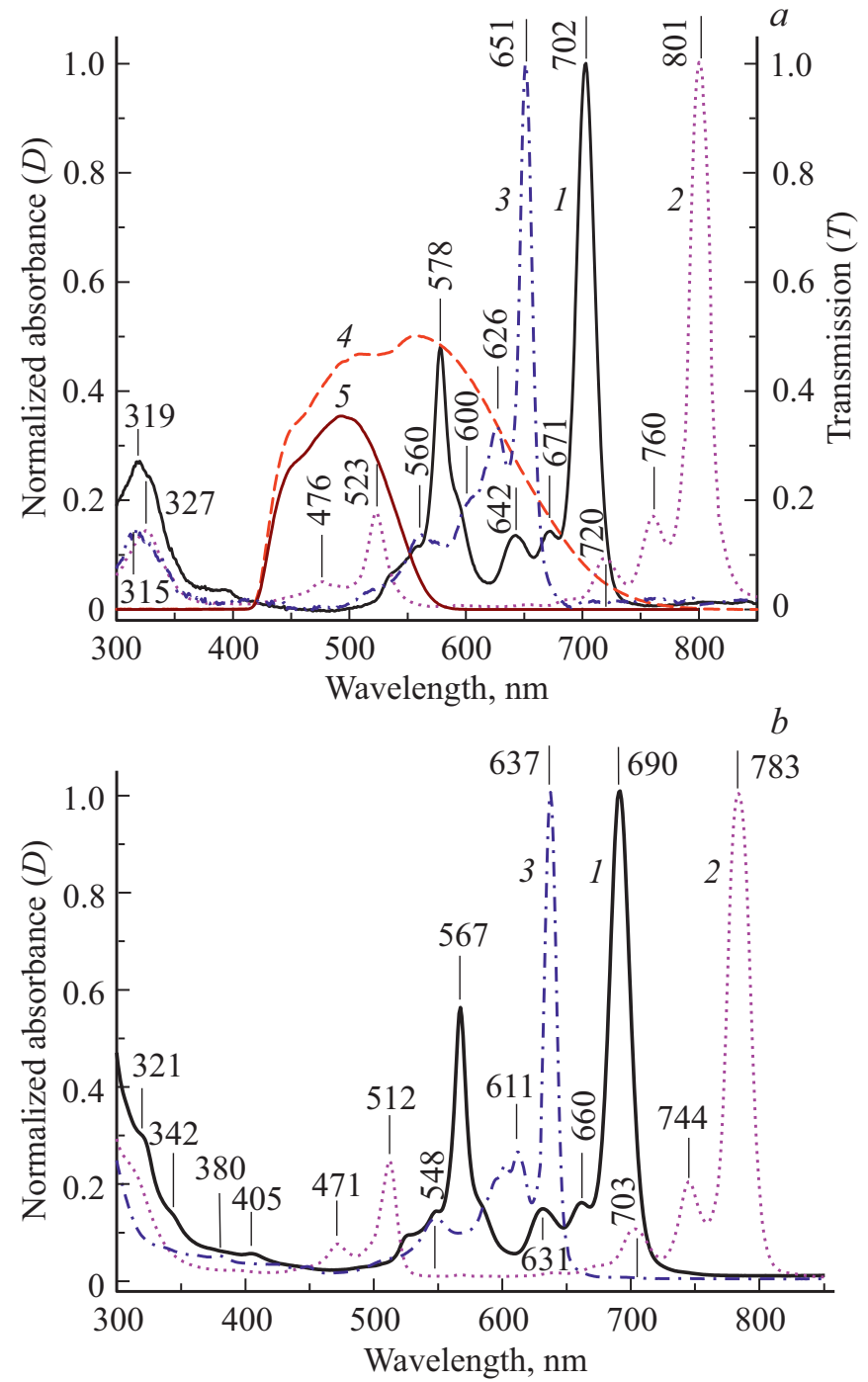

Рис. 1. Спектры поглощения растворов в МТГФ: $a-\operatorname{Pd} 1$ (1), $\operatorname{Pd} 2$ (2) и $\mathrm{Pd} 3$ (3); $b-\mathrm{Pt} 1$ (1), Pt2 (2) и Pt3 (3) при $293 \mathrm{~K}$; 4 и 5 - полосы пропускания стеклянных фильтров, через которые проходило возбуждающее излучение при продольном возбуждении образцов в Lumoscan.

При комнатной температуре в отличие от низкой $(77 \mathrm{~K})$ приведенные на рисунках спектры в большинстве случаев были получены „сшиванием“ спектров, записанных на обоих приборах: вблизи максимума полосы контуры брались с Lumoscan, в остальной спектральной области - c Fluorolog-3. На Lumoscan спектры измерялись в узкой области $(100-150 \mathrm{~nm})$ в течение $2-3 \mathrm{~min}$ (во избежание фоторазложения при возбуждении мощным излучением), на Fluorolog-3 спектры записывались в широкой спектральной области $(\sim 760 \mathrm{~nm})$ в течение 20-30 s. Регистрация осушествлялась при спектральной ширине щелей $14.0 \mathrm{~nm}$ на Fluorolog-3, $11.0 \mathrm{~nm}$ - на Lumoscan.

Контуры спектров фосфоресценции, записанные на обоих приборах при $77 \mathrm{~K}$ в широкой области
$(900-1600 \mathrm{~nm})$, совпадали с погрешностью не более 3-5\%, что свидетельствовало о правильности методик коррекции спектров, несмотря на разницу в оборудовании, применявшемся для коррекции, а также различие способов возбуждения и регистрации.

Электронные спектры поглощения растворов, а также спектры пропускания фильтров регистрировались на спектрофотометре Cary-500 Scan UV-Vis-NIR (Varian, США, Австралия). Квантовые выходы фосфоресценции $\varphi_{p}$ прозрачных растворов при 293 и $77 \mathrm{~K}$ оценивались относительным методом. В качестве эталона был принят раствор Pt3 в 2-метилтетрагидрофуране (МТГФ) (при 293 и $77 \mathrm{~K}$ значения $\varphi_{p}=0.053$ и $1.68 \%$ из [8]).

В качестве основного растворителя для спектральнолюминесцентных исследований использовался МТГФ фирмы Aldrich, хорошо растворяющий многие тетрапирролы и образующий прозрачное стекло при 77 К. Дополнительно использовались растворители толуол, диметилсульфоксид (ДМСО) и диметилформамид (ДМФА).

\section{Экспериментальные результаты}

На рис. 1 представлены спектры поглощения исследованных соединений в МТГФ при 293 К. Спектры нормированы к 1 в максимуме длинноволновой полосы. Спектры поглощения всех трех исследованных комплексов Pt представлены в работе [8] в виде рисунков (в МТГФ, толуоле и ДМСО) и в виде численных данных $\left(\lambda_{\max }, \lg \varepsilon\right)$ - в хлорбензоле и гексане. В [8] приведены также данные для комплексов $\mathrm{Pd}$ в хлорбензоле, а в работе [6] - для Zn1 в толуоле; спектры поглощения последнего комплекса в ДМСО даны там в рисунках. Эта информация позволяет оценить влияние на абсорбционные спектры растворителя и природы металла. Из данных по $\lg \varepsilon$ следует, в частности, что рис. 1 достаточно хорошо качественно представляет абсолютную интенсивность полос. Величина $\lg \varepsilon$ для длинноволновой полосы в хлорбензоле близка к 5.2, отклоняясь до 5.16 y Pt1 и до 5.37 у Pt3 (в гексане).

В случае металлокомплексов типа 1 спектры в толуоле и хлорбензоле близки, МТГФ и ДМФА дают небольшой гипсохромный сдвиг $(\sim 5 \mathrm{~nm})$ полос в видимой области. Здесь уместно отметить, что в работе [12] для алюминиевых комплексов фталоцианина (Рc) показана связь положения полос поглощения с донорным числом Гутмана (DN, cм. [13-15]) растворителя, а в шкале DN тетрагидрофуран имеет меньшее значение, что коррелирует с нашими данными по спектрам поглощения в МТГФ (метильная группа слабо влияет на DN).

В области аналога полосы Соре ситуация несколько сложнее и сдвиги больше, особенно в шкале частот, но всё же различия небольшие.

Замена одного изоиндольного фрагмента в молекуле металлофталоцианина (MPc) на гидрированное пиррольное кольцо приводит к понижению симметрии сопряженной системы молекулы от $D_{4 h}$, точной или прибли- 
женной (в зависимости от структурных факторов), и снятию двукратного вырождения возбужденного состояния $S_{1,2}$ (обычно обозначаемого $Q_{1,2}$ или просто $Q$ ), ответственного за интенсивную длинноволновую полосу $Q(0-0) \mathrm{MPc}$, и расщеплению её на две компоненты $Q_{1}$ и $Q_{2}$, или $Q_{x}$ и $Q_{y}$, при наличии приближенной симметрии $C_{2 v}$.

В ряду Zn1, Pd1 и Pt1 имеет место повышение уровня $S_{1}\left(Q_{x}\right)$ от $13870 \mathrm{~cm}^{-1}(721 \mathrm{~nm})$ на $380 \mathrm{~cm}^{-1}$ (до $702 \mathrm{~nm}$ ) и на $620 \mathrm{~cm}^{-1}$ (до $690 \mathrm{~nm}$ ). Уровень $Q_{y}$ соответственно повышается от $16780 \mathrm{~cm}^{-1}$ на $520 \mathrm{~cm}^{-1}$ и на $860 \mathrm{~cm}^{-1}$. Для М2 и М3 соответственно из данных рис. 1 получаются аналогичные сдвиги при переходе от Pd к Pt: $290 \mathrm{~cm}^{-1}\left(Q_{x}\right), 410 \mathrm{~cm}^{-1}\left(Q_{y}\right)$ и $340 \mathrm{~cm}^{-1}\left(Q_{x}\right)$, $390 \mathrm{~cm}^{-1}\left(Q_{y}\right)$.

В спектрах поглощения Zn1 полоса $Q_{y}$ имеет сложную структуру, что интерпретировано как проявление сложного вибронного аналога резонанса Ферми ([6] и ссылки там). Данные рис. 1 для Pd1 и Pt1 показывают, что этот эффект здесь значительно слабее - полоса $Q_{y}$ уширена несильно, усиление соседних полос незначительно. Причиной этого является возрастание энергетического интервала $Q_{y}-Q_{x}, \Delta E_{Q x y}$, - система как бы выходит из резонанса при замене атома $\mathrm{Zn}$ атомами $\mathrm{Pd}$ и Pt. Значения $\Delta E_{Q x y}$ составляют соответственно 2910 (Zn1), 3060 (Pd1) и $3140 \mathrm{~cm}^{-1}$ (Pt1).

Такое же гидрирование второго, противоположного, пиррольного кольца (приближенная симметрия $D_{2 h}$ ) приводит к батохромным сдвигам $Q_{x}(0-0)$ полос на $99 \mathrm{~nm}$, т.е. $1760 \mathrm{~cm}^{-1}$ (Pd) и на $93 \mathrm{~nm}\left(1720 \mathrm{~cm}^{-1}\right)(\mathrm{Pt})$ и к возрастанию $\Delta E_{Q x y}$ до $6640 \mathrm{~cm}^{-1}$ (т. е. на $3580 \mathrm{~cm}^{-1}$ ) для $\mathrm{Pd} 2$ и до $6760 \mathrm{~cm}^{-1}$ (т.е. на $3620 \mathrm{~cm}^{-1}$ ) для $\mathrm{Pt} 2$. Гидрирование соседнего пиррольного кольца (приближенная симметрия $C_{2 v}$ ), наоборот, приводит к гипсохромным сдвигам $Q_{x}(0-0)$ полос на $51 \mathrm{~nm}$, т.е. $1120 \mathrm{~cm}^{-1}(\mathrm{Pd} 3)$ и на $53 \mathrm{~nm}\left(1210 \mathrm{~cm}^{-1}\right)(\mathrm{Pt} 3)$ и уменьшению $\Delta E_{Q x y}$ до $2500 \mathrm{~cm}^{-1}(\mathrm{Pd} 3)$ и $2550 \mathrm{~cm}^{-1}(\mathrm{Pt} 3)-$ по данным для растворов в МТГФ. Если интенсивность $Q_{x}(0-0)$ полос остается высокой, то интенсивность $Q_{y}(0-0)$ полос уменьшается, особенно у М3.

Описанные изменения аналогичны наблюдаемым при гидрировании пиррольных колец у металлопорфиринов.

В области аналога полосы Соре у комплексов гидропорфиразинов регистрируется диффузная полоса с двумя максимумами. Для Zn1 измерения поляризации флуоресценции выявили частичную поляризацию этих близких полос по осям $x$ и $y$, но различия в значениях степени поляризации невелики [6]. Это интерпретировано как проявление здесь нескольких электронных переходов с различной поляризацией. Квантово-химический расчет молекулы Mg1 также выявил в этой области несколько электронных переходов [6].

Как следовало из оценок [8], основанных на влиянии структурных факторов на величину интервала $S_{1}-T_{1}\left(\Delta E_{S T}\right)$, 0-0-полоса фосфоресценции Pt2 должна была иметь $\lambda_{\max } \sim 1500 \mathrm{~nm}$. В соответствии с этим предположением вначале с помощью Fluorolog-3 при исполь-

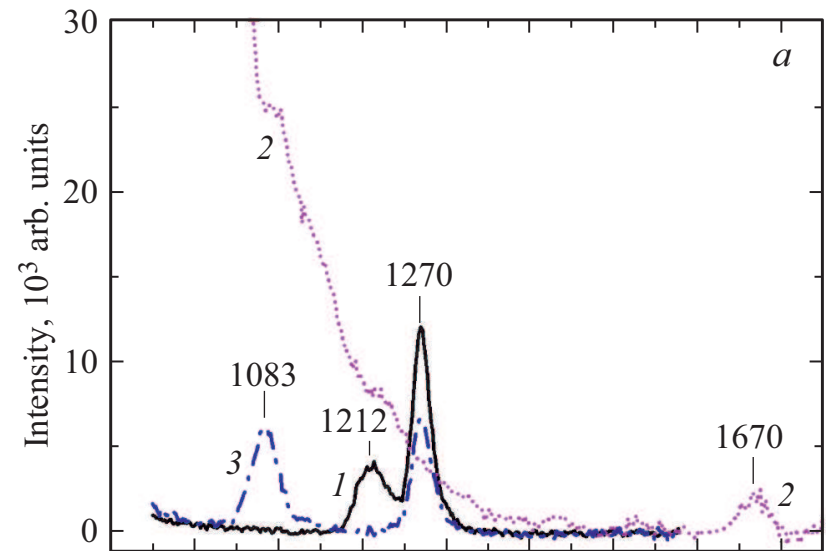

90010001100120013001400150016001700 Wavelength, nm

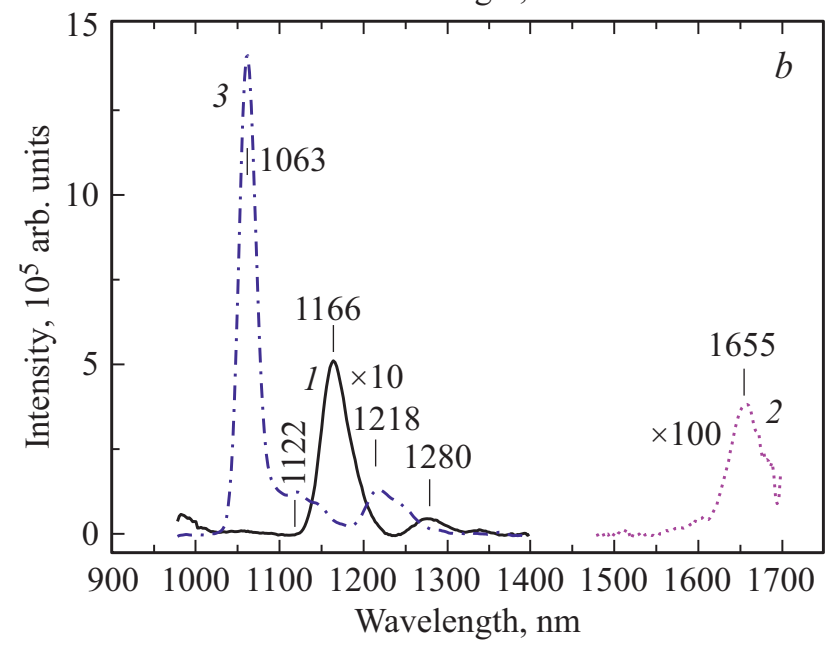

Рис. 2. Спектры фосфоресценции растворов Pd1 (1), Pd2 (2) и $\operatorname{Pd} 3$ (3) в МТГФ при $293 \mathrm{~K}(a)$ и $77 \mathrm{~K}(b) ; \lambda_{\text {exc }}=578$ (1), 523 (2) и $560 \mathrm{~nm}(3)$.

зовании матричного InGaAs-детектора, охлаждаемого жидким азотом, был зарегистрирован спектр с полосой $\lambda_{\max }=1520 \mathrm{~nm}$ для раствора Pt2 в толуоле при $293 \mathrm{~K}$. Однако впоследствии по ряду причин мы вынуждены были для получения спектров фосфоресценции использовать и Lumoscan. Этими причинами были: затруднения с получением на Fluorolog-3 полосы Pd2, ожидаемой из подобных оценок в области 1600-1700 nm, из-за высокого уровня рассеянного и возбуждающего света; более высокая точность определения максимумов полос в области 1000-1100 nm и лучше отлаженная методика сравнения пиковых интенсивностей при 293 и $77 \mathrm{~K}$ на Lumoscan, чем на Fluorolog-3. В связи с применением новой техники эксперимента естественным развитием работы был повтор исследований остальных бензоконденсированных гидропорфиразинов, изучавшихся в работе [8] и при стационарном, и при лазерном импульсном возбуждении.

На рис. 2 и 3, а также в табл. 1 представлены основные результаты исследований, сопоставлены спектры 

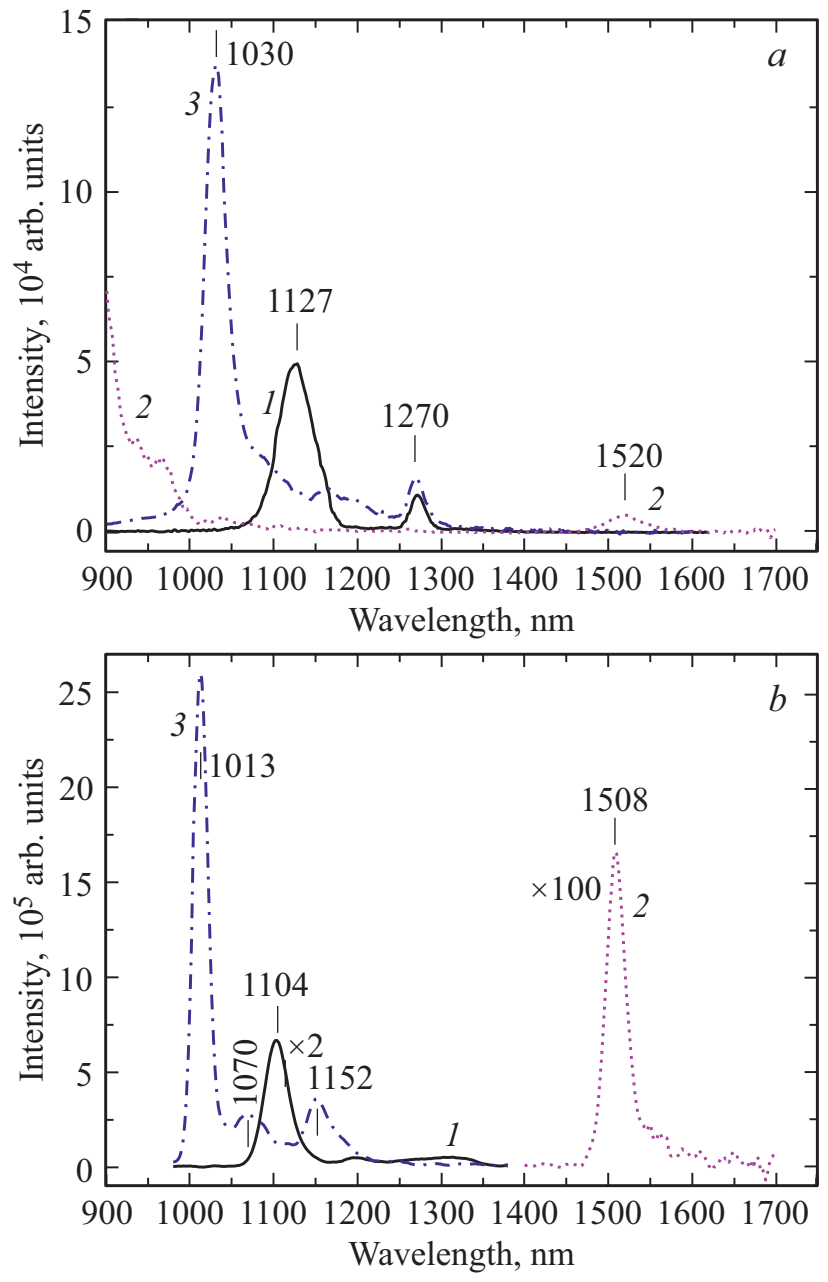

Рис. 3. Спектры фосфоресценции растворов Pt1 (1), Pt2 (2) и $\mathrm{Pt} 3$ (3) в МТГФ при $293 \mathrm{~K}(a)$ и $77 \mathrm{~K}(b)$; $\lambda_{\mathrm{exc}}=567(1)$, 512 (2) и $550 \mathrm{~nm}(3)$.

фосфоресценции исследованных палладиевых и платиновых комплексов в МТГФ при комнатной и низкой температурах (293 и $77 \mathrm{~K})$. Приведенные на рис. 2 и 3 спектры построены в единой шкале и, таким образом, по ним можно сравнивать пиковые интенсивности каждого из образцов при условии одинаковой интенсивности возбуждения (значения оптической плотности $(D)$ растворов, соответствующие $\lambda_{\text {ехс }}$, различались не более чем в 2 раза). Как можно легко убедиться, благодаря применению новой техники эксперимента даже при стационарном возбуждении удалось получить спектры фосфоресценции более высокого качества и в более широком спектральном диапазоне, чем в [8].

Главным результатом настоящего исследования является то, что удалось зарегистрировать полосы слабой фосфоресценции и $\mathrm{Pt} 2(1520 \mathrm{~nm})$, и особенно 0-0полосу Pd2, расположенную еще дальше в БИК диапазоне $(1670 \mathrm{~nm})$. Как уже сказано, сначала в стандартном варианте комплектации на Fluorolog-3 была зарегистрирована полоса $1520 \mathrm{~nm}$, а затем (в специаль- ном нестандартном варианте) на Lumoscan - полоса $1670 \mathrm{~nm}$. Одна из трудностей при регистрации полосы $1670 \mathrm{~nm}$, кроме помехи от неотфильтрованной части возбуждающего и рассеянного света, заключалась в резком падении чувствительности InGaAs-детекторов в области $1600-1700 \mathrm{~nm}$. Подтверждением того факта, что полоса $1520 \mathrm{~nm}$ принадлежит именно 0-0-фосфоресценции Pt2, служит хорошее совпадение PES и спектра поглощения Pt2 в МТГФ (рис. 4). Отметим, что и для всех остальных исследуемых соединений, кроме Pd2, наблюдалось достаточно близкое совпадение PES и электронных спектров поглощения.

Из-за технических трудностей PES Pd2 нам не удалось получить. Однако можно привести ряд соображений в пользу того, что полоса испускания при $1670 \mathrm{~nm}$ действительно является $0-0$-полосой фосфоресценции Pd2. Во-первых, положение этой полосы хорошо согласуется с указанными выше оценками, давшими верный результат для Pt2; во-вторых, при переходе от 293 к $77 \mathrm{~K}$ 0-0-полоса фосфоресценции $\mathrm{Pt} 2$ и рассматриваемая полоса $\mathrm{Pd} 2$, имея близкие значения полуширин, почти одинаково гипсохромно смещаются (соответственно на 12 и $15 \mathrm{~nm}$ ), а также сужаются. В-третьих, эта полоса не связана с неотфильтрованной частью возбуждающего и рассеянного света, что проверено при использовании в качестве образца чистого растворителя.

Из рис. 2, $a$ и 3, $a$ видно, что спектр люминесценции Pt2 и, особенно Pd2, в МТГФ при $293 \mathrm{~K}$ характеризуется уширенной полосой при $\lambda<900 \mathrm{~nm}$, которая, как оказалось впоследствии, принадлежит флуоресценции. Последнюю мы позднее подробно исследовали (только при комнатной температуре). Для остальных четырех соединений полос флуоресценции ни при $293 \mathrm{~K}$, ни при $77 \mathrm{~K}$ в области $\lambda$ короче $900 \mathrm{~nm}$ мы не обнаружили. Что касается этих соединений, то следует отметить, что общей закономерностью для них является присутствие в их спектрах при $293 \mathrm{~K}$ полосы люминесценции синглетного кислорода $1270 \mathrm{~nm}$, возникающей при переходе из состояния ${ }^{1} \Delta_{g}$. Для платиновых комплексов интенсивность полосы $1270 \mathrm{~nm}$ ниже, чем полосы 0-0-фосфоресценции, а для палладиевых комплексов, наоборот, - несколько выше. При понижении температуры этих растворов до $77 \mathrm{~K}$ полосы люминесценции синглетного кислорода исчезают, что свидетельствует о контролируемом поступательной диффузией переносе электронной энергии на молекулы кислорода.

Из рис. 2, $a$ и 3, $a$ также видно, что спектры фосфоресценции Pd1, Pd3, Pt1 и Pt3 представляют собой узкие 0 -0-полосы со слабо выраженными вибронными полосами с длинноволновой стороны, перекрывающимися с полосами люминесценции синглетного кислорода. Максимумы 0-0-полос спектра фосфоресценции комплексов $\mathrm{Pt}(1127,1520,1030 \mathrm{~nm})$ гипсохромно сдвинуты относительно аналогичных значений для комплексов $\mathrm{Pd}$ $(1212,1670,1083 \mathrm{~nm})$. Наибольшей интенсивностью при 293 K характеризуется 0-0-полоса фосфоресценции Pt3, 


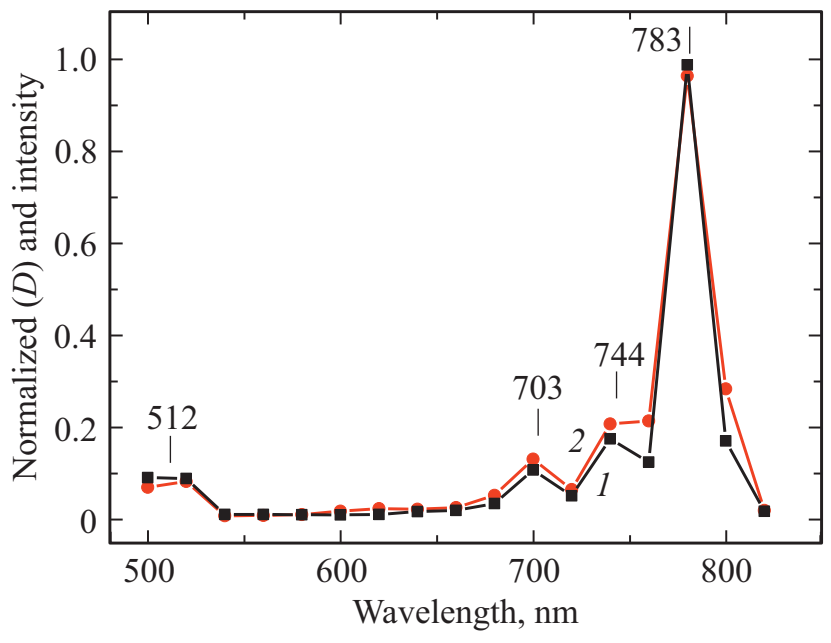

Рис. 4. Спектры поглощения (1) и возбуждения фосфоресценции $(2)\left(\lambda_{\text {mon }}=1520 \mathrm{~nm}\right)$ раствора Pt2 в МТГФ при $293 \mathrm{~K}$ (построены по точкам с интервалом $20 \mathrm{~nm}$ ).

наименьшей - Pd2. При $293 \mathrm{~K}$ расположение соединений в порядке убывания интенсивности 0-0-полосы: Pt3, Pt1, Pd3, Pt2, Pd1, Pd2. В конкретных условиях наших экспериментов интенсивность $0-0$-полос спектров фосфоресценции на рис. 2 и 3 качественно передает соотношение квантовых выходов фосфоресценции, $\varphi_{p}$, у разных соединений. Численные значения $\varphi_{p}$, измеренные нами, представлены в табл. 1.

При понижении температуры от 293 до $77 \mathrm{~K}$ (рис. $2, b$ и $3, b)$ квантовый выход значительно возрастает: в большей степени для Pd1, Pd3, чем Pt1, Pt3, а для Pt2 и Pd2 возрастание невелико $-\sim 3$ раза (табл. 1 ); происходит гипсохромный сдвиг и сужение главных полос, а также усиление колебательной структуры. При $77 \mathrm{~K}$ расположение соединений в порядке убывания интенсивности несколько изменяется и имеет вид: Pt3, Pd3, Pt1, Pd1, $\mathrm{Pt} 2, \mathrm{Pd} 2$. Наибольшими абсолютными значениями $\varphi_{p}$ характеризуются Pt3 и Pd3 (табл. 1) - соответственно 1.68 и $1.17 \%$, наименьшими - Pt2 и $\mathrm{Pd} 2$ при $293 \mathrm{~K}$ $(0.0007$ и $0.0014 \%)$.

Минимальные значения $\varphi_{p}$ для Pt2 и $\mathrm{Pd} 2$ компенсируются, как уже упоминалось, наличием флуоресценции у этих комплексов, которая не зарегистрирована для четырех остальных исследуемых соединений. На рис. $5, a$ и $5, b$ сопоставлены нормированные спектры: поглощения, возбуждения флуоресценции (FES) и флуоресценции (FS) растворов Pd2 и Pt2 в МТГФ при $293 \mathrm{~K}$. FES на рис. 5 хорошо согласуются со спектрами поглощения. Это свидетельствует о том, что зарегистрированные полосы с максимумами 814 и $799 \mathrm{~nm}$ являются именно флуоресценцией, а также о достаточно высокой чистоте веществ. Спектры флуоресценции лишь приближенно зеркально симметричны области перехода $G \rightarrow Q_{x}$ спектра поглощения. Значения полуширины спектра флуоресценции трехкратно превышают аналогичные параметры спектра поглощения. Значения стоксовых сдвигов составляют для $\mathrm{Pd} 2$ и $\mathrm{Pt} 2$ соответственно 14 и $16 \mathrm{~nm}$. Нарушение зеркальной симметрии спектров поглощения и флуоресценции свидетельствует о перестройке молекулы в возбужденном $S_{1}$-состоянии.

В ходе проводимых исследований были накоплены некоторые сведения о фотостабильности и растворимости исследуемых комплексов, а также о влиянии растворителей на эти свойства для четырех растворителей: МТГФ, толуол, ДМСО и ДМФА. По убыванию фотостабильности исследуемые платиновые и палладиевые комплексы располагаются следующим образом: Pt1, Pt2, Pt3 и Pd1, Pd2, Pd3, а по снижению степени растворимости - Pt3, Pt1, Pt2 и Pd3, Pd1, Рd2. При этом соответствующие платиновые комплексы более фотостабильны, чем палладиевые. По растворимости МТГФ, толуол примерно одинаковы, ДМФА, ДМСО примерно одинаковы. По зависимости фотостабильности от растворителя в порядке её снижения: толуол, МТГФ, ДМФА, ДМСО. Замечено, что растворимость в ДМФА и ДМСО сильно зависит от содержания в них воды,
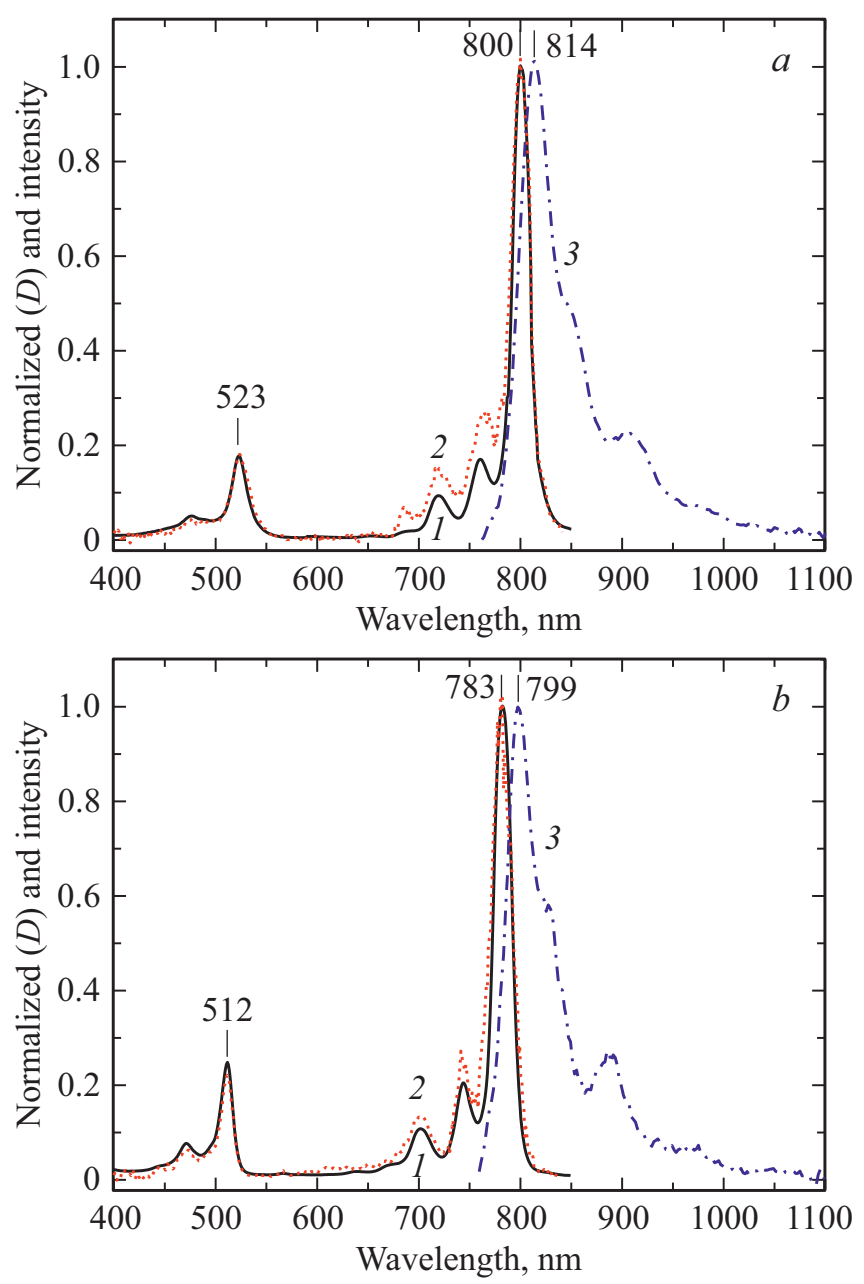

Рис. 5. Нормированные спектры поглощения (1), возбуждения флуоресценции (2) и флуоресценции (3) растворов в МТГФ при $293 \mathrm{~K}: a-\mathrm{Pd} 2\left(\lambda_{\text {mon }}=900 \mathrm{~nm}, \lambda_{\text {exc }}=523 \mathrm{~nm}\right) ; b-$ Pt2 $\left(\lambda_{\text {mon }}=880 \mathrm{~nm}, \lambda_{\mathrm{exc}}=512 \mathrm{~nm}\right)$. 
Таблица 1. Фотофизические характеристики комплексов бензозамещенных гидропорфиразинов с Pd и $\mathrm{Pt}$, измеренные при стационарном возбуждении

\begin{tabular}{c|c|c|c|c|c|c|c}
\hline Вещество & Растворитель & $T, \mathrm{~K}$ & $\lambda_{Q x}, \lambda_{Q y}, \mathrm{~nm}$ & $\lambda_{p}^{00}, \mathrm{~nm}$ & $\varphi_{p}, \%$ & $\Delta_{\lambda}^{T}, \mathrm{~nm}$ & $\Delta_{V}^{T}, \mathrm{~cm}^{-1}$ \\
\hline Pd1 & МТГФ & 293 & 702,578 & 1212 & 0.0013 & 46 & 325 \\
& & 77 & - & 1166 & 0.043 & & \\
\hline Pd2 & МТГФ & 293 & 801,523 & 1670 & 0.0007 & 15 & 54 \\
& & 77 & - & 1655 & 0.0021 & & \\
\hline Pd3 & МТГФ & 293 & 651,560 & 1083 & 0.0023 & 20 & 173 \\
& & 77 & - & 1063 & 1.17 & & \\
\hline Pt1 & МТГФ & 293 & 690,567 & 1127 & 0.0154 & 23 & 185 \\
& & 77 & - & 1104 & 0.126 & & \\
\hline Pt2 & МТГФ & 293 & 783,512 & 1520 & 0.0014 & 12 & 52 \\
& & 77 & - & 1508 & 0.0045 & & 17 \\
\hline Pt3 & МТГФ & 293 & 637,548 & 1030 & 0.053 & 17 & 163 \\
& & 77 & - & 1013 & 1.68 & & \\
\hline Рt2 & толуол & 293 & 784,512 & 1517 & 0.0016 & - &
\end{tabular}

уменьшаясь с его увеличением. МТГФ вместо толуола нами выбран только по причине его способности образовывать хорошее стекло при замораживании.

\section{Обсуждение результатов}

Как отмечено выше, главный результат работы обнаружение фосфоресценции комплексов $\mathrm{Pd}$ и $\mathrm{Pt}$ c дибензогидропорфиразинами в средней части ближней ИК области, с аксимумами $0-0$-полос $\left(\lambda_{p}^{00}\right)$ около 1650 и $1500 \mathrm{~nm}$ соответственно, что является, насколько нам известно, рекордными значениями для молекулярной фосфоресценции тетрапирролов. Для сравнения

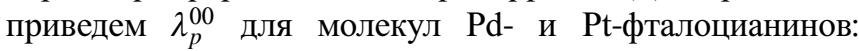
990 nm [16-18] (PdPc) и 945 nm (PtPc) [18] (при 77 K), а также для комплексов октабутокси-2,3-нафталоцианина $\left(\mathrm{Nc}(\mathrm{OBu})_{8}\right)$ [19] (при $\left.293 \mathrm{~K}\right)-1343$ и $1265 \mathrm{~nm}$ для $\mathrm{Pd}$ и $\mathrm{Pt}$ комплексов соответственно.

Вместе с тем полученные результаты с учетом литературных данных позволяют проследить на примере палладиевых и некоторых платиновых комплексов ряда тетрапирролов влияние структурных факторов на энергию состояния $T_{1}$. В молекулах бензогидропорфиразинов сочетаются три фактора, способные существенно влиять на электронную структуру и физико-химические свойства при сохранении в молекуле внутреннего 16членного кольца сопряженных связей: гидрирование пиррольных колец, азазамещение и бензозамещение (в более общем случае - аренозамещение).

Следует также отметить, что в предыдущей работе [8] для трех соединений: $\operatorname{Pd} 1, \operatorname{Pd} 3$ и Pt1 фосфоресценция не была зарегистрирована при стационарном возбуждении (была зарегистрирована при импульсном лазерном возбуждении). В данной работе этот пробел заполнен, причем результаты двух методов (стационарного и импульсного) хорошо согласуются между собой.

Спектры фосфоресценции в МТГФ измерены при комнатной температуре и $77 \mathrm{~K}$. Как обычно, при $77 \mathrm{~K}$ 0-0-полосы фосфоресценции сужены и смещены в коротковолновую сторону. В табл. 1 приведены величины этих сдвигов $\left(\Delta_{\lambda}^{T}\right.$ в nm и в $\left.\mathrm{cm}^{-1}\right)$. Для аналогов бактериохлорина они значительно меньше, чем для хлоринов и изобактериохлоринов. В первом случае молекулы исследованных тетрапирролов имеют приближенную симметрию $D_{2 h}$, и их дипольный момент близок к нулю, а во втором случае (симметрия $C_{2 v}$ ) дипольный момент молекул может быть ненулевым. Как известно, молекулы люминофора, обладающие ненулевым дипольным моментом, в возбужденном электронном состоянии могут претерпевать понижение энергии в результате сольватационных эффектов, если дипольный момент изменяется в результате перехода в возбужденное состояние (другие виды межмолекулярных взаимодействий проявляются слабее). В замороженных твердых (rigid) средах этот эффект не имеет места. Поэтому полученные данные о слабом влиянии температуры на спектры фосфоресценции молекул $\mathrm{Pd} 2$ и $\mathrm{Pt} 2$ можно связывать с отсутствием у них дипольного момента. Для $\mathrm{Pd} 1$ сдвиг больше, чем для Pt1, что может быть связано с меньшим радиусом атома Pd. В остальных случаях сдвиги для комплексов $\mathrm{Pd}$ и $\mathrm{Pt}$ близки.

Обсуждение влияния молекулярной структуры на фосфоресценцию комплексов тетрапирролов с $\mathrm{Pd}$ и $\mathrm{Pt}$ следует начать с общего замечания. В предыдущих наших работах основное внимание обращалось на величину интервала $S_{1}-T_{1}, \Delta E_{S T}$. Такой подход оправдан, когда для некоторых из исследуемого ряда соединений спектр фосфоресценции не зарегистрирован и является предметом поиска. Однако большее значение и четкий 

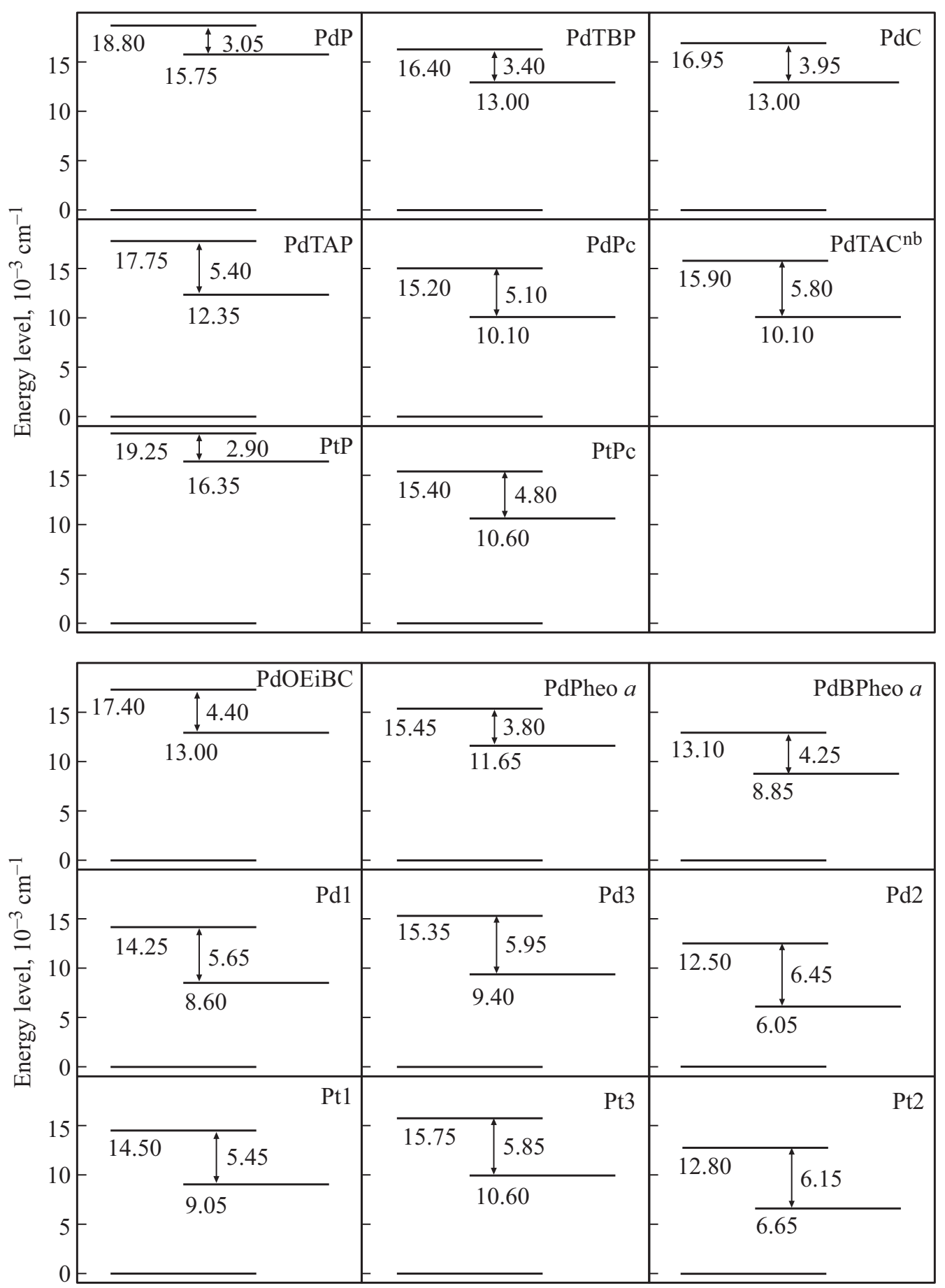

Рис. 6. Трехуровневые диаграммы (уровни $S_{0}, T_{1}, S_{1}$ ) для комплексов молекул тетрапирролов с палладием и платиной. Ссылки на литературные данные приведены в тексте, полные названия соединений даны в табл. 2.

физический смысл имеет величина энергии состояния $T_{1}$. Именно эта величина в первую очередь определяет способность вещества участвовать в межмолекулярных фотопроцессах. В настоящей работе основное внимание обращается на величину $E_{T_{1}}$.

Первые исследования низкотемпературной фосфоресценции хлорофиллоподобных молекул были выполнены Кальвинои и Дорафом, обнаружившими фосфоресцен- цию хлорофилла $b$ и металлокомплексов тетрафенилпорфина [20,21]. В работах Беккера и Эллисон [22,23] было изучено влияние природы центрального атома металла на интенсивность фосфоресценции металлопорфиринов и найдено, что наибольшей интенсивностью обладают комплексы палладия и платины. Комплексы этих металлов предпочтительны для поиска фосфоресценции конкретного макроцикла, что и было сделано 
в настоящей работе, как и в работе [8]. Отметим, что фосфоресценция свободных оснований порфиринов менее интенсивна, чем у комплексов с легкими металлами [24,25].

На рис. 6 результаты наших исследований $\mathrm{Pd}$ и $\mathrm{Pt}$ бензогидропорфиразинов представлены в виде трехуровневых диаграмм. Вместе с литературными данными для родственных структур использованы опубликованные данные для Рd-порфина [26,27], Pd-тетрабензопорфина [17], Рd-хлорина [27], Pdоктаэтилизобактериохлорина [28], Рd-феофитина $a$ [29], Pd-бактериофеофитина $a$ [29], Рd-тетраазапорфина [30], Pd-фталоцианина [16-18], Pt-фталоцианина [18], Pdнорборненотетраазахлорина [31].

Данные об энергии состояния $T_{1}$ для палладиевых и некоторых платиновых комплексов тетрапирролов с различной молекулярной структурой макроциклов (табл. 2) показывают, что в случае молекул тетрапирролов с углеродными метиновыми мостиками тетраазазамещение приводит к понижению уровня $T_{1}$ на $2100 \mathrm{~cm}^{-1}$. Такой же сдвиг дает гидрирование одного пиррольного

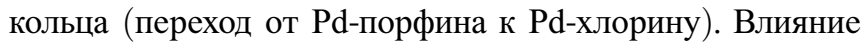
гидрирования второго пиррольного кольца можно определить по данным [28] для Рd-октаэтилхлорина и $\mathrm{Pd}-$ октаэтилизобактериохлорина - уровень $T_{1}$ повышается на $250 \mathrm{~cm}^{-1}$. Гидрирование второго, противоположного, пиррольного кольца понижает уровень $T_{1}$ на $2800 \mathrm{~cm}^{-1}$,

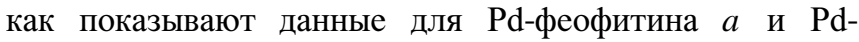
бактериофеофитина $a$.

В случае молекул с азотными мостиками (тетраазазамещенных) наблюдаются сопоставимые сдвиги. Так, у Рd-тетраазапорфина энергия уровня $T_{1}$ на $2750 \mathrm{~cm}^{-1}$ меньше, чем у Pd-порфина. Бензозамещение (переход к PdPc) понижает его ещё на $2250 \mathrm{~cm}^{-1}$. Такова же величина сдвига при гидрировании пиррольного кольца (полная аналогия с тетрапирролами, у которых мостики метиновые!).

Для бензогидропорфиразинов нельзя ожидать полной аналогии с дигидро- и тетрагидропорфиразинами, так как у последних отсутствуют бензольные кольца, входящие в сопряженную систему макроцикла. Как следует из результатов настоящей работы, замена одного изоиндольного фрагмента на гидрированное пиррольное кольцо понижает уровень $T_{1}$ на $1500 \mathrm{~cm}^{-1}$, замена ещё одного, противоположного, изоиндольного фрагмента (транс- изомер) понижает энергию $T_{1}$ уровня ещё на $2550 \mathrm{~cm}^{-1}$. Это значение сопоставимо с понижением уровня $T_{1}$ у бактериофеофитина на $2800 \mathrm{~cm}^{-1}$. Для цисизомера получается повышение уровня $T_{1} \mathrm{Ha} 800 \mathrm{~cm}^{-1}$ относительно Pd1.

На основании накопленной информации о спек-

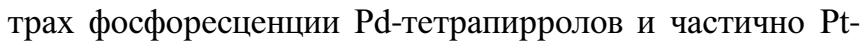
тетрапирролов можно сделать вывод о приближенной аддитивности влияния азазамещения, бензозамещения и гидрирования пиррольных колец на энергию уровня $T_{1}$.

Как видно из табл. 2, данные по смещению для комплексов платины - объектов настоящего исследова-
Таблица 2. Энергия уровня $T_{1}$ для комплексов палладия и платины с молекулами тетрапирролов при $77 \mathrm{~K}$

\begin{tabular}{l|c|c}
\hline Вещество & $E_{T 1}, \mathrm{~cm}^{-1}$ & Литература \\
\hline Рd-порфин & 15750 & {$[26,27]$} \\
Pt-порфин & 16350 & {$[26]$} \\
Рd-тетрабензопорфин & 13000 & {$[17]$} \\
Pd-хлорин & 13000 & {$[27]$} \\
Рd-октаэтилхлорин & 12750 & {$[28]$} \\
Рd-октаэтил- & 13000 & {$[28]$} \\
изобактериохлорин & & \\
Рd-феофитин $a$ & 11650 & {$[29]$} \\
Рd-бактериофеофитин $a$ & 8850 & {$[29]$} \\
Рd-тетраазапорфин & 12350 & {$[30]$} \\
Рd-фталоцианин & 10100 & {$[16-18]$} \\
Pt-фталоцианин & 10600 & {$[18]$} \\
Pd-норборненотетразахлорин & 10100 & {$[31]$} \\
Рd1 & 8600 & \\
Pt1 & 9050 & \\
Pd2 & 6050 & \\
Pt2 & 6650 & \\
Pd3 & 9400 & \\
Pt3 & 9900 &
\end{tabular}

ния - аналогичны таковым для комплексов палладия. Спектры фосфоресценции Рt-бензогидропорфиразинов смещены в коротковолновую сторону, $S-T$-интервал несколько уменьшен. Имеем соответственно для $\mathrm{Pd} 1$ $\Delta E_{S T}=5670 \mathrm{~cm}^{-1}$, для Pt1 $\Delta E_{S T}=5440 \mathrm{~cm}^{-1}$; для $\mathrm{Pd} 2$ и $\mathrm{Pt} 2$ - $6440 \mathrm{~cm}^{-1}$ и $6140 \mathrm{~cm}^{-1}$; для $\mathrm{Pd} 3$ и $\mathrm{Pt} 3-$ $5950 \mathrm{~cm}^{-1}$ и $5830 \mathrm{~cm}^{-1}$. Для комплексов фталоцианина аналогичный $S-T$-интервал составляет: PdPc $5100 \mathrm{~cm}^{-1}$ [16-18], PtPc $-4800 \mathrm{~cm}^{-1}$ [18].

Pd-порфирины ранее считались нефлуоресцирующими, но в работе [32] слабая флуоресценция была обнаружена. Флуоресценция PdPc была зарегистрирована

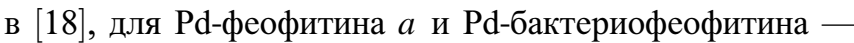
в [29], замещенного Рd-тетраазахлорина — в [33]. Данные о флуоресценции $\mathrm{PtNc}(\mathrm{OBu})_{8}$ и комплексов других переходных металлов с $\mathrm{Nc}(\mathrm{OBu})_{8}$ представлены в [19].

На рис. 5 представлены спектры БИК-флуоресценции основных объектов нашего исследования - $\mathrm{Pd} 2$ и $\mathrm{Pt} 2$. Они отличаются от типичных спектров флуоресценции металлокомплексов фталоцианинов и гидропорфиразинов небольшим уширением спектральных полос. Стоксов сдвиг (200-260 $\left.\mathrm{cm}^{-1}\right)$ несколько больше, чем для PdРс и Рd-бактериофеофитина $a\left(\sim 150 \mathrm{~cm}^{-1}\right)$.

Эти результаты можно сравнивать с данными работы [19] по БИК-флуоресценции $\left.\mathrm{PdNc}(\mathrm{OBu})_{8}\right)$ и $\operatorname{PtNc}(\mathrm{OBu})_{8} \quad\left(\lambda_{A}^{00}=827\right.$ и $\left.811 \mathrm{~nm}\right)$. Значения $\lambda_{F}^{00}-$ соответственно 873 и $879 \mathrm{~nm}$, стоксов сдвиг - 652 и $954 \mathrm{~cm}^{-1}$. Спектры флуоресценции значительно шире $Q(0-0)$-полосы поглощения. Авторы [19] связывают возрастание стоксова сдвига у комплексов Pt с изменением геометрии молекулы в состоянии $S_{1}$ (один из двух вариантов объяснения). Однако узость $Q(0-0)$-полосы 
поглощения показывает, что в „франк-кондоновском“ $S_{1}$-состоянии геометрия молекулы сохраняется, а изменения геометрии происходят в этом состоянии в результате межмолекулярных взаимодействий. У наших объектов стоксовы сдвиги значительно меньше.

\section{Заключение}

Применение современных методов регистрации электромагнитного излучения в БИК диапазоне позволило получить спектры ранее не наблюдавшейся фосфоресценции комплексов палладия и платины с трансоктаметилдибензогидропорфиразином - структурным аналогом бактериохлорофилла — при 77 и $293 \mathrm{~K}$. Определен квантовый выход фосфоресценции. Получены также спектры флуоресценции этих комплексов — тоже в ближнем ИК диапазоне.

С использованием результатов предшествующей работы [8] и литературных данных прослежено влияние структурных факторов на энергию нижнего триплетного уровня палладиевых и некоторых платиновых комплексов тетрапирролов. Сделан обобщающий вывод о приближенной аддитивности вкладов структурных факторов: тетраазазамещения, тетрабензозамещения, гидрирования одного пиррольного кольца и второго пиррольного кольца (как противоположного первому, так и соседнего с ним) - в энергию уровня $T_{1}$. Результаты работы имеют теоретическое значение для физики молекул класса тетрапирролов и создают необходимую основу для создания системы знаний, способной предсказывать фотофизические свойства новых химических соединений.

Практическому использованию фосфоресценции $\mathrm{Pd}$ и $\mathrm{Pt}$ металлокомплексов фталоцианина и его производных препятствует крайне низкий выход свечения ( 1\% даже у Pt-фталоцианина) [18], которая неизбежно уменьшается с продвижением в БИК область в силу возрастания вероятности безызлучательного размена энергии состояния $T_{1}$ на колебания молекул в основном состоянии. Впрочем, необходимо отметить как положительный момент в этом плане, что выход фосфоресценции Pt3 (1.68\%) выше, чем Pt-фталоцианина, несмотря на длинноволновый сдвиг 0-0-полосы от $945 \mathrm{~nm}$ у $\mathrm{Pt}$ фталоцианина до $1013 \mathrm{~nm} \mathrm{y} \mathrm{Pt3,} \mathrm{т.е.} \mathrm{на} 710 \mathrm{~cm}^{-1}$. Для Pd3 выход возрастает ещё больше относительно Pdфталоцианина: $1.17 \%$ против $0.3 \%$ (в четыре раза). Значения $\lambda_{p}^{00}$ соответственно $1063 \mathrm{~nm} \mathrm{и} 990 \mathrm{~nm}$, т.е. получается сдвиг на $700 \mathrm{~cm}^{-1}$ (табл. 1,2 и [18]). Вместе с тем область БИК диапазона $1.0-1.7 \mu \mathrm{m}$ весьма актуальна для практических применений в области оптоэлектроники и в биомедицинских исследованиях [34].

Следует отметить, что подавляющее большинство практических применений с участием комплексов $\mathrm{Pd}$ и $\mathrm{Pt}$ с тетрапирролами имеет место в области, где $\lambda<1000 \mathrm{~nm}$. Успехи в применении подобных комплексов в области $\lambda>1000 \mathrm{~nm}$ намного скромнее, так как для достижения этой цели, кроме высокого квантового выхода, нужно обеспечить еще и высокую фотостабильность. Среди исследованных нами комплексов самым фотостабильным оказался Pt1. Анализ результатов настоящей работы, а также $[8,34]$ и других авторов однозначно свидетельствует, что путем подбора внешних факторов (растворитель, матрица) и химической модификации можно значительно повысить квантовый выход и фотостабильность фосфоресценции металлокомплексов на основе тетрапирролов. Но удастся ли довести отмеченные характеристики до требуемых значений для практических приложений в области БИК диапазона $1.0-1.7 \mu \mathrm{m}$ остается пока неясным.

\section{Финансирование работы}

Результаты были получены в рамках выполнения задания 1.4.02 Государственной программы научных исследований Республики Беларусь „Фотоника, опто- и микроэлектроника“.

\section{Конфликт интересов}

Авторы заявляют, что у них нет конфликта интересов.

\section{Список литературы}

[1] Макарова Е.А., Королева Г.В., Лукьянеи Е.А. // ЖОХ. 2001. T. 71. 5 C. 874; Makarova E.A., Koroleva G.V., Luk'yanets E.A. // Russian J. General Chemistry. 2001. V. 71. N 5. P. 821. doi 10.1023/A:1012398427529

[2] Макарова Е.А., Королева Г.В., Лукьянеи Е.А. // Патент РФ 2188200, 2002.

[3] Fukuda T., Makarova E.A., Luk'yanets E.A., Kobayashi N. // Chem. Eur. J. 2004. V. 10. N 1. P. 117. doi $10.1002 /$ chem. 200305363

[4] Makarova E.A., Fukuda T. Luk'yanets E.A., Kobayashi N. // Chem. Eur. J. 2005. V. 11. N 4. P. 1235. doi $10.1002 /$ chem. 200400845

[5] Makarova E.A., Dzyuina E.V., Fukuda T., Kaneko H., Hashimoto N., Kikukawa Y., Kobayashi N., Lukyanets E.A. // Inorg. Chem. 2009. V. 48. N 1. P. 164. doi 10.1021/ic801552u

[6] Першукевич П.П., Волкович Д.И., Гладков Л.Л., Дудкин С.В., Кузьмицкий В.А., Макарова Е.А., Соловьев К.Н. // Опт. и спектр. 2017. Т. 123. С. 518; Pershukevich P.P., Volkovich D.I., Gladkov L.L., Dudkin S.V., Kuzmitsky V.A., Makarova E.A., Solovyev K.N. // Opt. Spectrosc. 2017. V. 123. P. 535. doi 10.1134/S0030400X17100198

[7] Арабей С.М., Гало Ж.-П., Ступак А.П., Павич Т.А., Макарова Е.А., Соловьев К.Н. // ЖПС. 2009. Т. 76. № 3. C. 376; Arabei S.M., Galaup J., Stupak A.P., Pavich T.A., Makarova E.A., Solovyov K.N. // J. Appl. Spectrosc. 2009. V. 76. N 3. P. 352. doi 10.1007/s10812-009-9187-х

[8] Першукевич П.П., Галиевский В.А., Сташевский А.С., Макарова Е.А., Лукьянеи, Е.А., Соловьев К.Н. // ЖПС. 2010. T. 77. № 6. C. 852; Pershukevich P.P., Galievsky V.A., Stasheuski A.S., Makarova E.A., Luk'yanets E.A., Solovyov K.N. // J. Appl. Spectrosc. 2011. V. 77. N 6. P. 790. doi 10.1007/s10812-011-9404-2 
[9] Kuzmitsky V.A, Makarova E.A., Pershukevich P.P., Shushkevich I.K., Solovyov K.N., Tusov V.B. // Chem. Phys. 2004. V. 298. P. 1. doi 10.1016/j.chemphys.2003.10.039

[10] Воропай Е.С., Самцов М.П., Радько А.Е., Каплевский К.Н., Першукевич П.П., Бельков М.В., Ермаличкий Ф.A. // Лазерная и оптико-электронная техника: сб. науч. ст. / Под ред. Манакая И.С. В. 10. Минск, Акад. Упр. При Президенте РБ, 2006. С. 200.

[11] Галиевский В.А., Сташевский А.С, Киселев В.В, Шабусов А.Н, Бельков М.В., Джсагаров Б.М. // ПТЭ. 2010. Т. 53. C. 109.

[12] Ou Z., Shen J., Kadish K.M. // Inorg. Chem. 2006. V. 45. P. 9569. doi 10.1021/ic061072f

[13] Gutmann V. // The Donor-Acceptor Approach in Molecular Interactions. NY:: PlenumPress, 1978.

[14] Фиалков Ю.Я. // Растворитель как средство управления химическим процессом. Л.: Химия, 1990.

[15] Cataldo F. // Eur. Chem. Bull. 2015. V. 4. P. 92. doi 10.17628/ecb.2015.4.92-97

[16] Соловьёв К.Н., Машенков В.А., Качура Т.Ф. // ЖПС. 1967. T. 7. C. 773 .

[17] Соловьёв К.Н., Машенков В.А., Качура Т.Ф. // Опт. и спектр. 1969. Т. 27. С. 50.

[18] Vincett P.S., Voigt E.M., Rieckhoff K.E. // J. Chem. Phys. 1971. V. 55. P. 4131.

[19] Kim J., Soldatova A.V., Rodgers M.A., Kenney V.E. // Polyhedron. 2013. V. 57. P. 64. doi 10.1016/j.poly.2013.04.022

[20] Calvin M., Dorough G.D. // Science. 1947. V. 105. P. 433.

[21] Calvin M., Dorough G.D. // J. Am. Chem. Soc. 1948. V. 70. P. 699.

[22] Allison J.B., Becker R.S. //J. Chem. Phys. 1960. V. 32. P. 1410.

[23] Becker R.S., Allison J.B. // J. Phys. Chem. 1965. V. 67. P. 2662.

[24] Цвирко М.П., Соловьёв К.Н, Градюшко А.Т., Дворников С.С. // ЖПС. 1974. Т. 20. С. 1528.

[25] Цвирко М.П., Соловьёв К.Н., Градюшко А.Т., Дворников С.С. // Опт. и спектр. 1975. Т. 38. С. 705.

[26] Eastwood D., Gouterman M. // J. Mol. Spectrosc. 1970. V. 35. P. 359.

[27] Егорова Г.Д., Машенков В.А., Соловьёв К.Н, Юикевич Н.А. // ЖПС. 1973. Т. 19. С. 838.

[28] Градюшко А.Т., Соловьёв К.Н, Туркова А.Е., Цвирко М.П. // Биофизика. 1975. Т. 20. С. 602.

[29] Лосев А.П., Кнюкшто В.Н., Кочубеева Н.Д., Соловьёв К.Н. // Опт. и спектр. 1990. Т. 69. С. 97.

[30] Машенков В.А., Соловьёв К.Н, Туркова А.Е., Юикевич Н.А. // ЖПС. 1974. Т. 21. С. 73.

[31] Бельков М.В., Грищук А.А., Дудкин С.В, Макарова Е.А., Першукевич П.П., Соловьёв К.Н. // ЖПС. 2010. Т. 77. № 2. C. 230; Belkov M.V., Grishchuk A.A., Dudkin,S.V., Makarova E.A., Pershukevich P.P., Solovyov K.N. // J. Appl. Spectrosc. 2010. V. 77. P. 213. doi 10.1007/s10812-010-93175.

[32] Callis J.B., Gouterman M., Jones Y.M., Henderson B.H. // J. Mol. Specrosc. 1971. V. 39. P. 410.

[33] Першукевич П.П., Шушкевич И.К., Макарова Е.А., Соловьёв К.Н. // ЖПС. 2008. Т. 75. № 5. С. 700; Pershukevich P.P., Shushkevich I.K., Makarova E.A., Solovyev K.N. // J. Appl. Spectrosc. 2008. V. 75. N 5. P. 706. doi 10.1007/s10812-008-9098-2

[34] Ibrahim-Ouali M., Dumur F. // Molecules. 2019. V. 24. N 7. P. 1412. doi 10.3390/molecules24071412 